ARTICLE

УАК 58.085+581.143.6:582.814

\author{
ВАИЯНИЕ АУКСИНОВ НА РИЗОГЕНЕЗ СОРТОВ АКТИНИАИИ КОАОМИКТА \\ В КУАЬТУРЕ IN VITRO \\ И.А. Бородулина ${ }^{1}$, Т.В. Пкаксина ${ }^{2}$ \\ 1 \\ ${ }^{2}$ ФБНУ «НИИСС им. М.А. Аисавенко», Барнаул, Россия. Email: tplaksina@mail.ru
}

Изучено влияние регуляторов роста ауксиновой природы на укоренение актинидии коломикта в культуре in vitro. Аанный виА актинидии является самым зимостойким, что в условиях Западной Сибири актуально, устойчив к вредителям. Отличается скороплодностью, начинает плодоносить с трехлетнего возраста. Этот вид живет более 50 мет. Объектами исследования явились две женские формы сортов актиниАии - Мома и Превосходная. Пцоды этих сортов имеют цилиндрическую форму, зеленого и темно-зеленого цвета, с продольными полосками. Вкус ягод у сорта Мома очень сладкий, с ананасным ароматом, у сорта Превосходная - кисловато-сладкий. У сорта Мома плоды при созревании не осыпаются. Эксплантами служили микрочеренки с Авумя почками. Испытано 12 вариантов питательных среА на основе среды Мурасиге-Скуга, Аополненные тремя разными регуляторами роста ауксиновой природы (ИМК, ИУК и НУК). Установлено, что на этапе укоренения целесообразно использовать относительно невысокие концентрации ауксинов: 0,5-1,0 мкМ НУК и 1,0 мкМ ИМК. Аیя кажАого сорта установлены эффективные концентрации и природа ауксина.

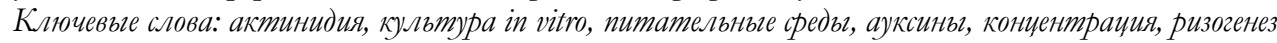

\title{
INFLUENCE OF AUXINS ON RIZOGENESIS OF ACTINIDIA KOLOMIKTA CULTIVARS IN CULTURE IN VITRO
}

\author{
I.D. Borodulina ${ }^{1}$, T.V. Plaksina ${ }^{2}$ \\ 1 Altai State University, Barnaul, Russia. Email: borodulina.irina@gmail.com \\ ${ }^{2}$ Lisavenko Research Institute of Horticulture for Siberia, Barnaul, Russia. Email: tplaksina@mail.ru
}

\begin{abstract}
The influence of growth regulators of axin nature on rooting of actinidia kolomikta in culture in vitro has been studied. This species of actinidia is the most-hardy that in conditions of Western Siberia is actual and resistant to pests as well. It differs by early ripening, bears from the three-year age. This species lives over 50 years. The objects of the study were two female forms of actinidia cultivars - Moma and Prevoskhodnaya. The fruits of these cultivars are cylindrical, green and dark-green, with longitudinal strips. The taste of berries of the cultivar Moma is very sweet, with pineapple aroma, as for Prevoskhodnaya - sour sweet. Fruits of the cultivar Moma are not deciduous, don't fell off at ripening. Micro cuttings with two buds were as explants. 12 variants of nutritional media on the base of medium Murashige Skoog, supplemented with growth regulators of auxin nature (IBA, IAA, NAA), were tested. It's established, that at the stage of rooting it's advisable to use relatively low concentrations of auxins: $0.5-1.0 \mu \mathrm{M}$ NAA and $1.0 \mu \mathrm{M}$ IBA. Effective concentrations and type of auxin are defined for each cultivar.

Key words: actinidia, culture in vitro, nutritional media, auxins, concentration, rizogenesis
\end{abstract}

\section{Следует цитировать / Citation:}

Бородулина И.А., Пцаксина Т.В. (2016). ВАияние ауксинов на ризогенез сортов Актинидии коломикта в культуре in vitro. Acta Biologica Sibirica, 2 (4), 102-109.

Borodulina, I.D., Plaksina, T.V. (2016). Influence of auxins on rizogenesis of Actinidia kolomikta cultivars in culture in vitro.

Acta Biologica Sibirica, 2 (4), 102-109.

Поступимо в редакцию / Submitted: 29.10.2016

Принято к публикации / Accepted: 24.11.2016

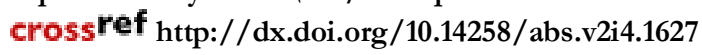

(C) Бородумина, Пиаксина, 2016

Users are permitted to copy, use, distribute, transmit, and display the work publicly and to make and distribute derivative works, in any digital medium for any responsible purpose, subject to proper attribution of authorship.

\section{(cc) $\mathrm{EY}$}

This work is licensed under a Creative Commons Attribution 3.0 License

\section{BВЕАЕНИЕ}

АктиниАия коломикта является нетрадиционной ягодной культурой с высоким содержанием в плодах биологически активных веществ и антиоксиАантов. Это поливитаминный виА. По своему мечебному спектру эта культура способна вытеснить многие медицинские препараты химического синтеза (Колбасина, 2003). Использование клонального микроразмножения позволяет достаточно быстро и в срок получать большое количество посадочного материала, особенно при ограниченном количестве маточных растений перспективных форм и сортов. Работы по изучению преАставителей 
рода Актинидия Lindl. в культуре in vitro ведутся в разных научных учереждениях нашей страны - это ВНИИГиСПР им. И.В. Мичурина (Муратова и Ар., 2010), ГБС им. Н.В. Цицина РАН (Молканова и др., 2014), НИИ садоводства Сибири им. М.А. Аисавенко (Плаксина, Бородулина, 2016) и Ар. ИсслеАователи отмечают востребованность и эффективность разработки методов устойчивого воспроизводства подобного рода культур Аля получения Аостаточного количества посаАочного материала, с одной стороны, а также Аля сохранения и изучения генофонда, с Аругой стороны.

Целью Аанной работы явилось изучение влияния ауксинов на ризогенез представителей рода АктиниАия в культуре in vitro.

\section{МАТЕРИААЫ И МЕТОАЫ ИССАЕАОВАНИЙ}

Работа проводицась в ФГБНУ «НИИСС» им. М.А. Аисавенко, в маборатории биотехнологии и цитологии. Объектами исследования явились две женские формы перспективных сортов актинидии коломикта - Превосходная и Мома. Методы биотехнологических исследований базировались на к^ассических приемах работы с культурами изолированных тканей и органов растений (Бутенко, 1999). Укоренение проводили на питательной среде по прописи Мурасиге и Скуга с уменышенным вдвое содержанием макросолей (1/2MC) (Murashige, Skoog, 1962), Аополненной ауксинами в разцичной концентрации: индолилмасляная кислота (ИМК), инАОлилуксусная кислота (ИУК) и $a$-нафтилуксусная кислота (НУК). Всего было испытано 12 вариантов питательных среА. В каждом варианте на среды помещалось по 5-10 эксплантов. Культивирование осуществляли при фотопериоде 16/8часов (Аень/ночь), освещенности 3 тыс. Аюкс, температуре $25^{\circ} \mathrm{C}$. Показания снимали через 3-4 недели. Э^ементы учёта: количество корней (шт./экспл.), Алина корней (см), наличие корней второго порядка (+/-), высота побега (см), количество Аистьев (шт./экспл.). Математическую обработку Аанных осуществ яли стандартными методами с использованием пакета программ Microsoft Office Excel 2007.

\section{РЕЗУАЬТАТЫ ИССАЕАОВАНИЙ И ИХ ОБСУЖАЕНИЕ}

АктиниАия относится к культурам, относительно легко укореняемым в условиях in vitro (Матушкина, Пронина, 1989). ОАнако, Е.В. Малаева (2008) отмечает, что экспланты a. kolomikta менее активно развиваются на всех стаАиях микроразмножения по сравнению с $a$. arguta и a. polygama. Изучение влияния ИМК на образование корней показало, что Аля обоих сортов наилучшие результаты были получены на среде с добавлением ИМК в концентрации 1 мкМ (рис. 1). Количество образовавшихся корней у растений-регенерантов сорта Мома на этой среде статистически значимо отличалось от всех остальных вариантов. А^я сорта Превосходная внесение ИМК в концентрации 0,5 и 2,0 мкМ оказывало фактически одинаковое вАияние на индукцию корнеобразования (9,3-11,1 шт./ экспл.).

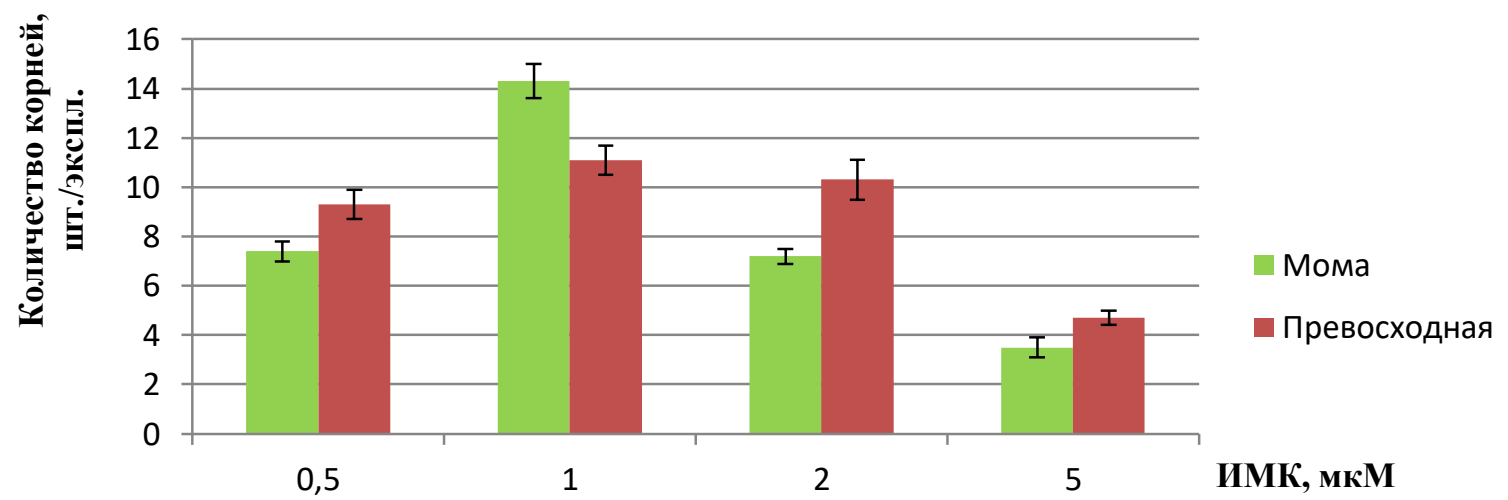

Рис. 1. ВАияние концентрации ИМК на интенсивность ризогенеза сортов а. коломикта в культуре in vitro

Использование больших концентраций ИМК (5,0 мкМ) снижало активность ризогенеза у микрорастений изучаемых сортов. При этом образование корней происходило быстрее (в течении 2-3 недель), но уменьшилось их количество от 3 до 4 шт./экспл., так как в основании микрочеренка было отмечено сильное разрастание калиуса, который тормозил Аальнейшее развитие корней. У образовавшихся корней отсутствовали корни второго порядка. На Аанной среде у регенерантов обоих сортов образовывались возАушные корни.

Изучение влияния НУК на корнеобразование показало, что максимальное количество корней у

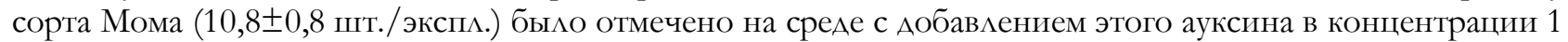
мкМ. БАизкие значения $(9,4 \pm 0,9$ шт./экспл.) у Аанного сорта фиксировались на среАе с 0,5 мкМ НУК. Повышение концентрации НУК Ао 2,0 и 5,0 мкМ незначительно снижало корнеобразование Ао 7,6士0,5

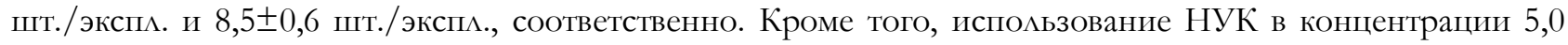
мкМ приводицо к интенсивному калцусообразованию и возникновению воздушных корней. 
А^я сорта Превосходная оптимальной оказалась питательная среда с добавлением 0,5 мкМ НУК, так как на ней отмечены максимальные значения образованных корней $(14,7 \pm 1,1$ шт./эксп .) среди всех

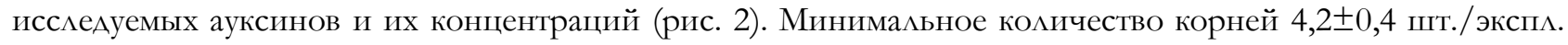
фиксировалось в варианте с использованием 5,0 мкМ НУК, наблюАалось интенсивное развитие калмуса в основании микрочеренка, так же как и у сорта Мома.

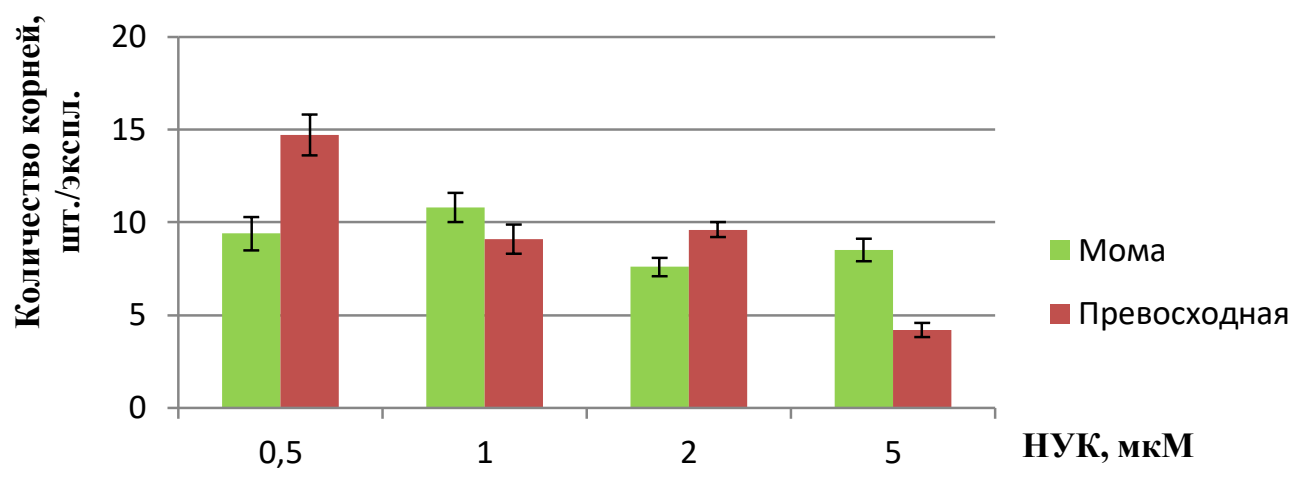

Рис. 2. ВАияние концентрации НУК на интенсивность ризогенеза сортов а. коломикта в культуре in vitro

Анализ данных по изучению влияния ИУК на индукцию ризогенеза выявиц, что наиболее эффективными Аля укоренения сортов оказались варианты с 0,5 и 1,0 мкМ этого ауксина (рис. 3). А^я

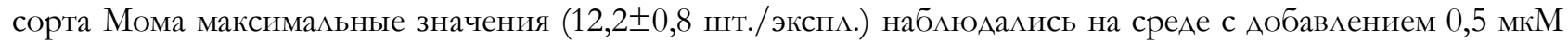
ИУК. При повышении концентрации ауксина до 1,0 мкМ количество образовавшихся корней оставалось на достаточно высоком уровне $(10,8 \pm 0,7$ шт./экспл.). А^я сорта Превосходная наиболее эффективной оказалась среда с 1,0 мкМ. Количество корней на этой среде составило 12,6 $\pm 0,7$ шт./экспл., что явилось оАним из кучших показателей Аля всех вариантов среА.

Наименее эффективным Аля сорта Мома оказалось повышение концентрации ИУК Ао 2,0 и 5,0

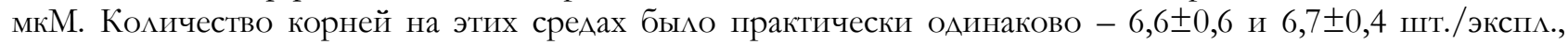
соответственно. При этом так же, как и с Аругими ауксинами, присутствие в среде 5 мкМ ИМК вызывало образование возАушных корней у обоих сортов.

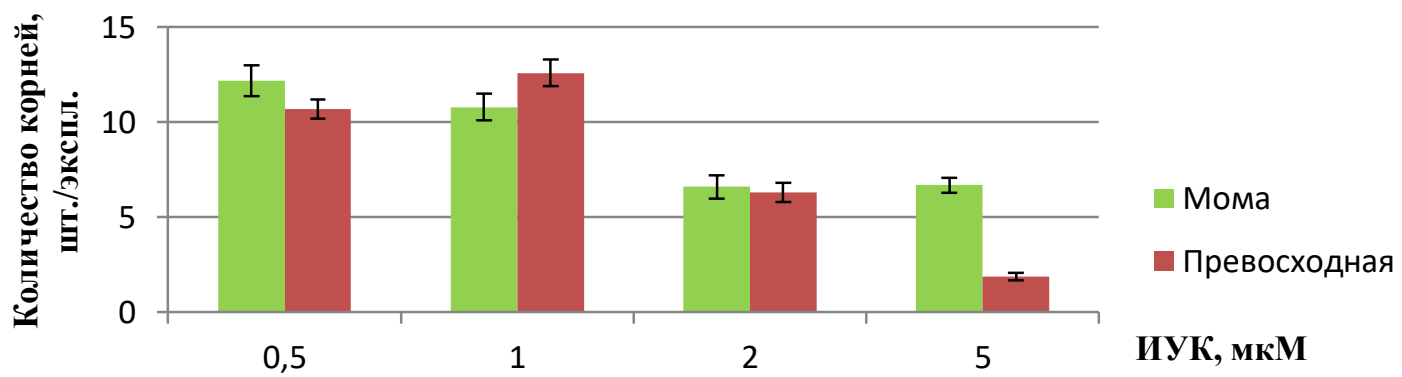

Рис. 3. ВАияние концентрации ИУК на интенсивность ризогенеза сортов а. коломикта в культуре in vitro

Таким образом, наименьшие концентрации ИУК (0,5 и 1,0 мкМ) способствовали наибольшему образованию корней, а их повышение (Ао 2,0 и 5,0 мкМ) ингибировало ризогенез. В целом, концентрации исследуемых ауксинов оказали значительное влияние на количество и качество образовавшихся корней у исследуемых сортов. Наибольшее их количество было образовано на среАах с наименьшими концентрациями - 0,5 и 1,0 мкМ; наименьшее - при повышенных концентрациях всех рассмотренных ауксинов (2,0 и 5,0 мкМ), которые вызывали индукцию каллусогенеза (рис. 4). Учитывая сортоспецифичность можно отметить, что Аля сорта Мома оптимальными явАяются концентрации с 0,5-1,0 мкМ, Аля сорта Превосходная - 0,5-2,0 мкМ. Все используемые ауксины в концентрации 5,0 мкМ вызывали индукцию воздушных корней, которые формировались не только ближе к основанию, но и по всей нижней части побега, в том числе и у основания мистьев. Следовательно, Аанная концентрация ауксинов оказалась не подходящей Аля данного вида растения. С.А. Муратова с соавторами (2010) также отмечает эффективность использования низких концентраций ИМК $(0,5-1,0$ мг / $)$ Аля укоренения сорта Пцоская а. коломикта в культуре in vitro. 


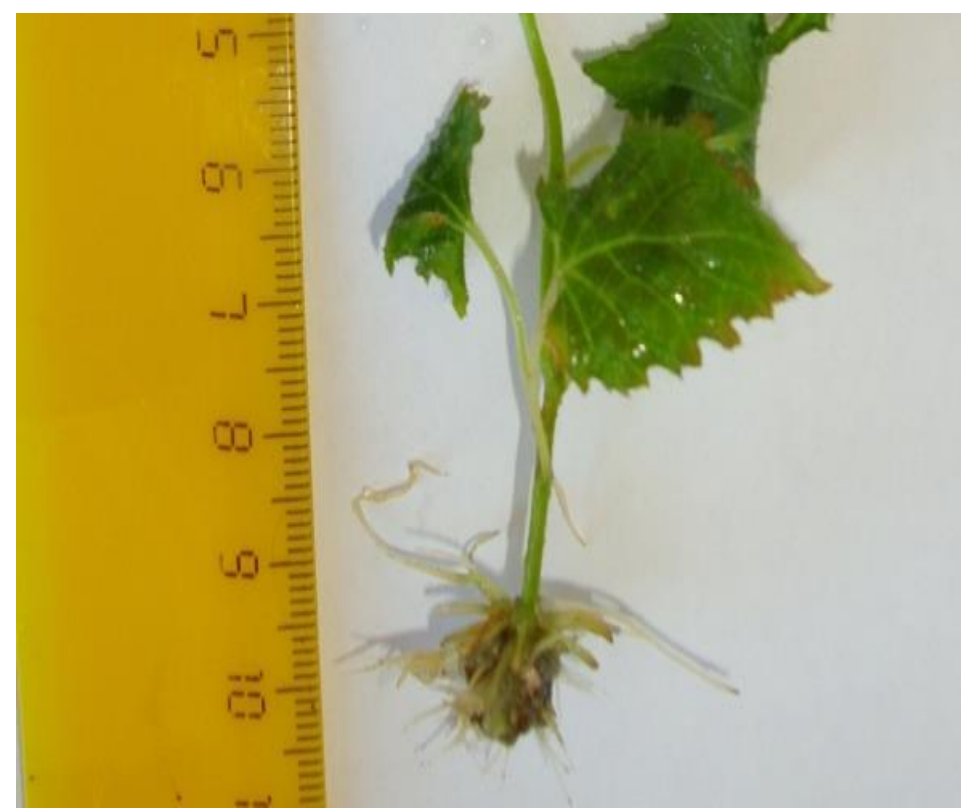

Рис. 4. Развитие кациуса у основания побега растения-регенеранта сорта Мома при укоренении в культуре in vitro

Изучая вАияние разных типов и концентраций ауксинов на Алину образуемых корней у растенийрегенерантов сортов а. коломикта, было отмечено, что в целом, Алина корней во всех вариантах находилась в пределах 2-3,5 см.

Алина корней растений-регенерантов сорта Мома в вариантах с ИМК различалась незначительно от 2,5 до 3,0 см, тогАа как Аля сорта Превосходная более удачным было использование относительно невысоких концентраций Аанного ауксина: 2,7-3,0 см в присутствии 0,5 и 1,0 мкМ ИМК против 2,0-2,2 см при 2,0 и 5,0 мкМ. Максимальная Алина корней $(3,0 \pm 0,1 \mathrm{~cm})$ у микрорастений сорта Мома фиксировалась при использовании ИМК в концентрации 0,5 мкМ, а у сорта Превосходная - на среде с Аобавлением 1,0 мкМ И (рис. 5).

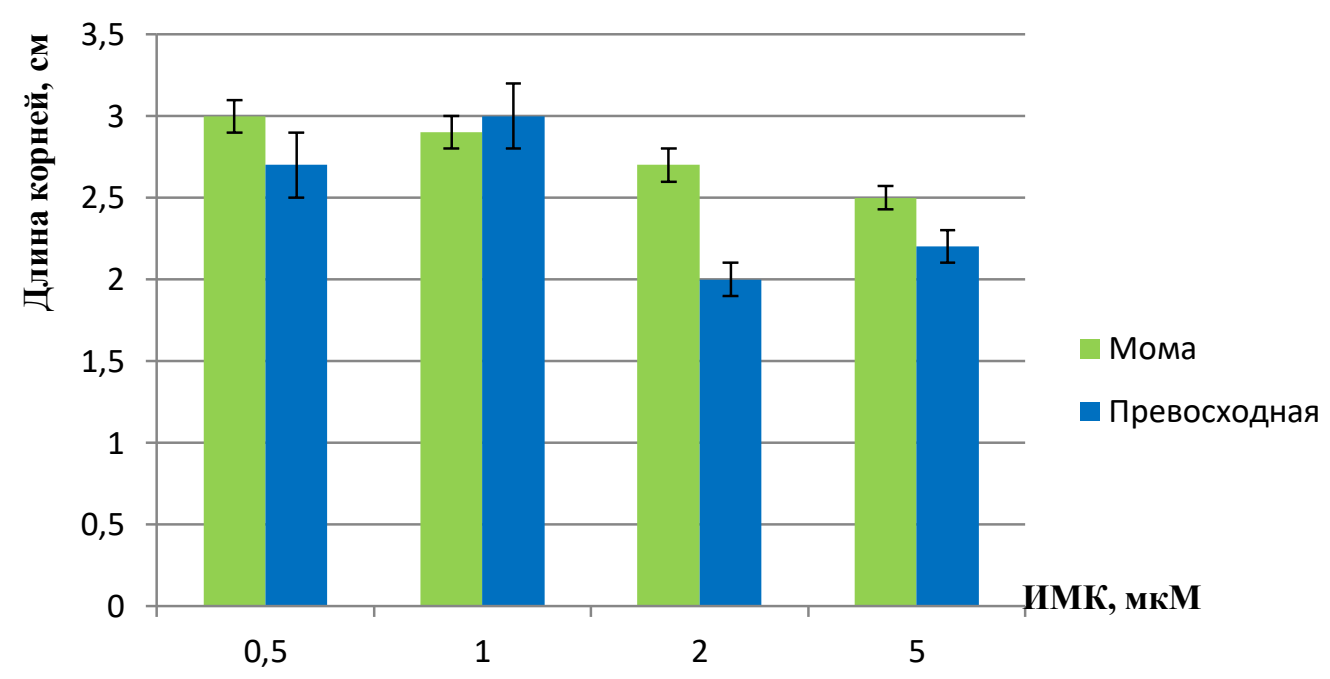

Рис. 5. ВАияние концентрации ИМК на Алину корней растений-регенерантов сортов а. коломикта в культуре in vitro

ВАияние НУК на Алину корней среди всех исследуемых ауксинов оказалось наиболее продуктивным, именно на среАах с Аобавлением этого гормона формировались наиболее Алинные корни у обоих сортов (рис. 6), при этом корни были хорошего качества (наличие корней второго поряАка, отсутствие утолщенных корней). 

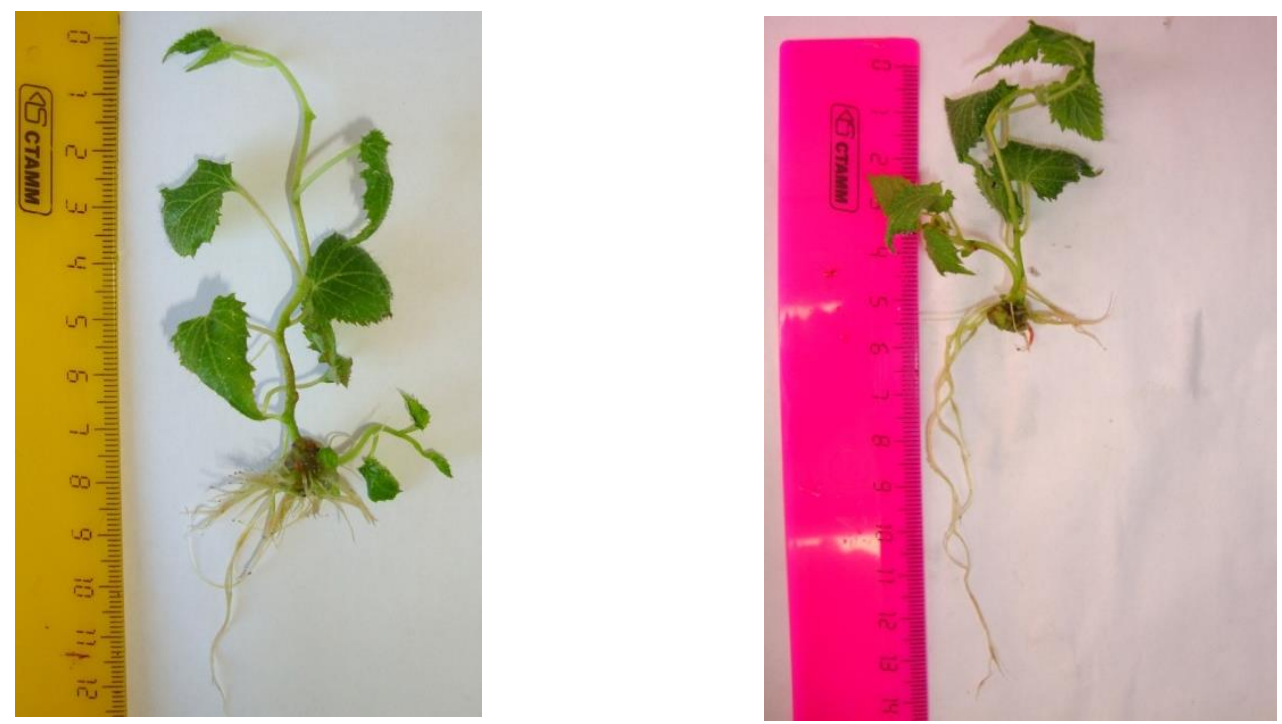

Рис. 6. Укорененные растения-регенеранты а. коломита сортов Мома (слева) и Превосходная (справа)

Максимальная Алина корней у сорта Мома среди всех изученных вариантов отмечалась на среде с Аобавлением 1,0 мкМ НУК и составляла $3,5 \pm 0,08$ см (рис. 7). На этой же среде было зафиксировано и Аостаточно большое количество корней $(10,8 \pm 0,8$ шт./экспл.). У сорта Превосходная самые Алинные

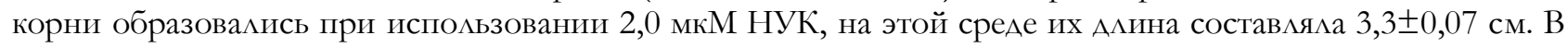
остальных вариантах (с 0,5; 1,0 и 5,0 мкМ НУК) Алина корней была практически одинаковой (около 2,5 см) и на 1 см меньше максимального значения.

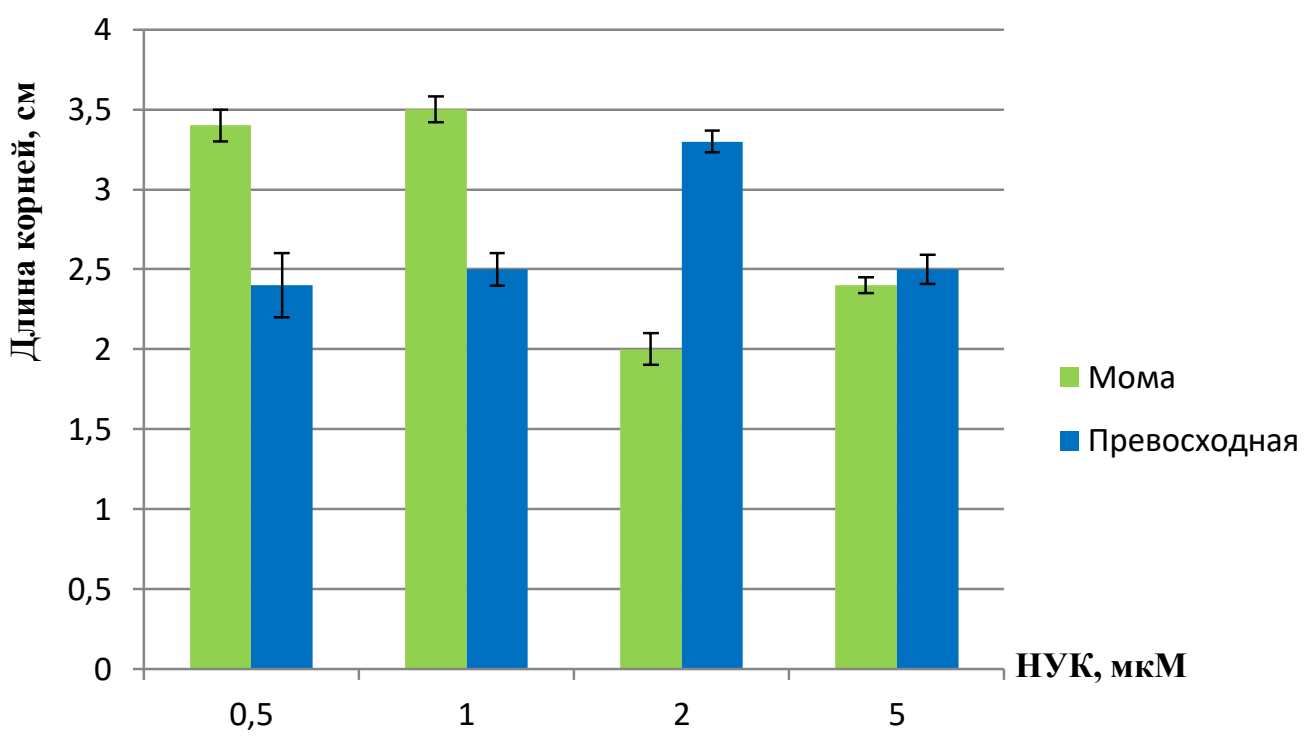

Рис. 7. ВАияние концентрации НУК на Алину корней растений-регенерантов сортов а. коломикта в культуре in vitro

ИУК, в отличие от НУК, оказала наименьшее влияние на стимуляцию роста корней в Алину. На средах с этим регулятором роста отмечались самые низкие показатели (от 1,6 до 2,7 см), особенно у микрорастений сорта Превосходная.

Более Алинные корни у сорта Мома формировались в вариантах с 0,5 мкМ ИМК, при этом Алина образовавшихся корней, в среднем, составила $2,7 \pm 0,1$ см. При использовании Аругих концентраций ИМК значения были ниже на 0,3 см и в целом мало отличались Аруг от Аруга (рис. 8). Аля сорта Превосходная максимальная Алина корней наблюдалась в присутствии 2,0 мкМ Аанного ауксина и состав яяла $2,6 \pm 0,08$ см.

Среди всех рассмотренных ауксинов с концентрацией 1,0 мкМ, ИУК оказалась менее эффективной по изучаемому признаку. Высокая концентрация регулятора роста $(5,0$ мкМ) ингибировала рост корней и изменяла их морфологию. 


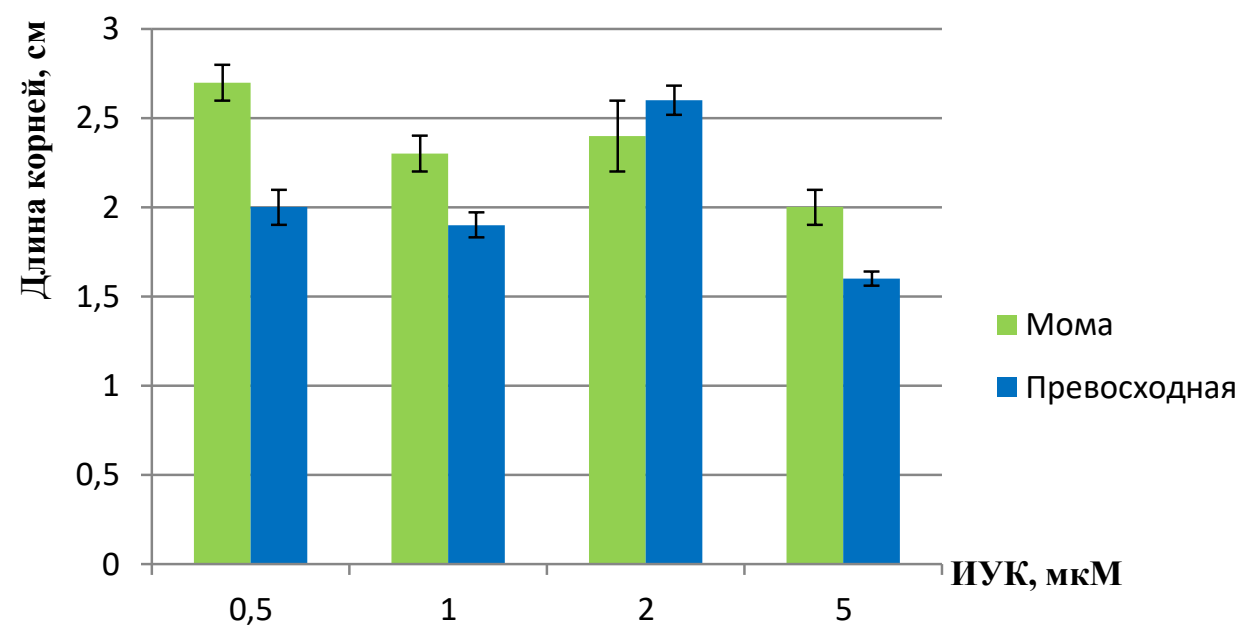

Рис. 8. ВАияние концентрации ИУК на Алину корней растений-регенерантов сортов а. коломикта в культуре in vitro

При укоренении растений-регенерантов важно учитывать и Аругие морфологические показатели микрочеренков, такие как высота побега и количество Аистьев на нем. Используемый тип и концентрация ауксинов не Аолжны оказывать тормозящее действие на их рост и развитие.

При изучении влияния ауксинов на высоту побега при укоренении отмечено, что все экспланты микрочеренков при культивировании на Аанных среАах вытягивались в Алину. Прирост побега на всех используемых средах составил около 1,0-2,5 см. В целом, все среды Аля укоренения оказывали положительное влияние на морфологию растений-регенерантов.

Наиболее высокие побеги для сорта Мома формировались на средах с 0,5, 1,0 и 2,0 мкМ ИМК $(2,5 \pm 0,06 ; 2,6 \pm 0,08$ и 2,6 $\pm 0,1$ см, соответственно) и при использовании 0,5 и 2,0 мкМ НУК $(2,7 \pm 0,1$ и

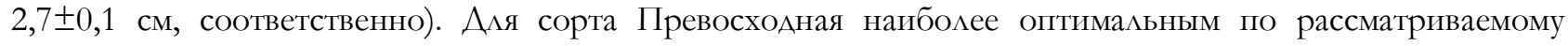
признаку стало применение 0,5 мкМ НУК. Этот тип ауксина в Аанной концентрации стимулироваА максимальную высоту побега, которая в среднем составила $3,1 \pm 0,2$ см (рис. 9). На этой же среде Аля Аанного сорта отмечалось максимальное количество корней $(14,7 \pm 1,1$ шт./экспц.).

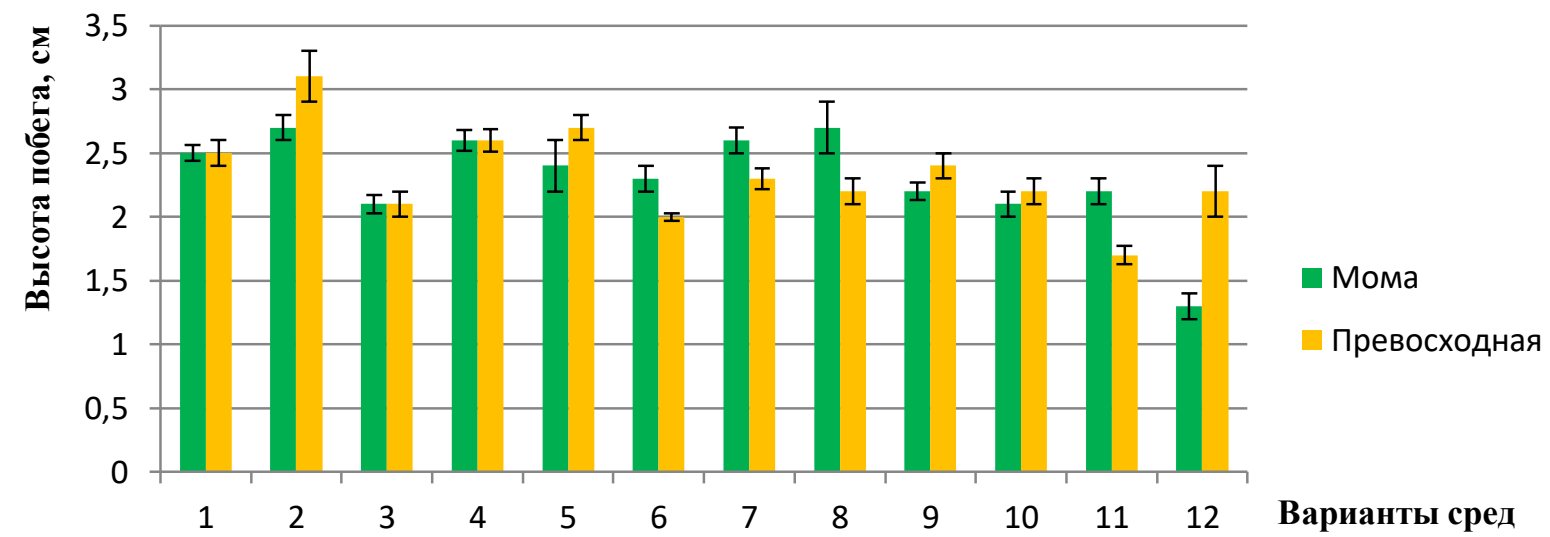

Рис. 9. ВАияние типа и концентрации ауксинов на высоту побегов растений-регенерантов сортов а. коломикта при укоренении в культуре in vitro

Условные обозначения: 1 - 0,5 мкМ ИМК; 2 - 0,5 мкМ НУК; 3 - 0,5 мкМ ИУК; 4 - 1 мкМ ИМК; 5 - 1 мкМ НУК; 6 - 1 мкМ ИУК; 7 - 2 мкМ ИМК; 8 - 2 мкМ НУК; 9 - 2 мкМ ИУК; 10 - 5 мкМ ИМК; 11 - 5 мкМ НУК; 12 - 5 мкМ ИУК

Анализ Аанных выявил, что концентрации используемых ауксинов незначительно влияют на этот показатель, а зависит от типа ауксина. Наименьшие результаты получены на средах с Аобавлением ИУК. Так, Аля сорта Мома самая низкая высота побега отмечалась на среАах с 0,5 и 5,0 мкМ ИУК $(2,1 \pm 0,07$ и $1,3 \pm 0,1$ см), а на средах с 1,0 и 2,0 мкМ ИУК значения быми невысокие: $2,3 \pm 0,1$ и 2,2 $\pm 0,07$ см, соответственно. Использование 5,0 мкМ ИМК так же не вызывало значительного роста побегов у сорта Мома $(2,1 \pm 0,1 \mathrm{~cm})$.

ISSN 2412-1908 (Online). Acta Biologica Sibirica. 2016. 2 (4). 
Микрорастения сорта Превосходная формировали короткие низкие побеги при использовании 0,5

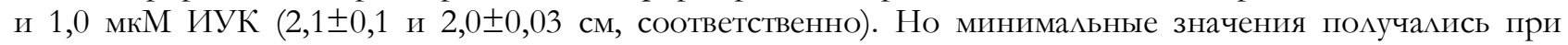
культивировании микрочеренков на среде с 5,0 мкМ НУК - 1,7 $\pm 0,07$ см.

Количество мистьев у растений-рагенерантов на этапе укоренения варьировало от 4,0 Ао 8,0 шт./экспл. На рисунке 10 показано, что у обоих сортов статистически значимо вылеляются показатели

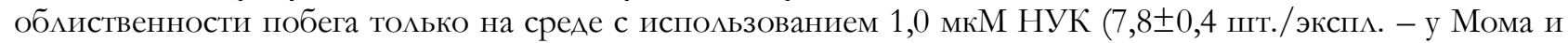

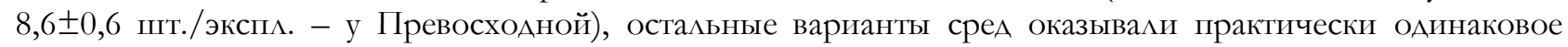
влияние на образование листьев.

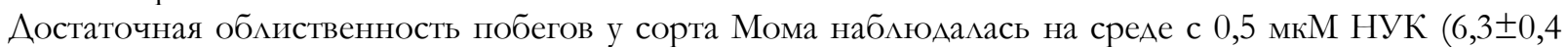

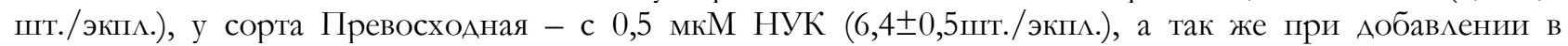

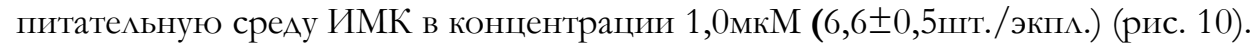

Наименьшие показатели Аля обоих исследуемых сортов наблюдались на средах с 5,0 мкМ всех типов ауксинов, а так же при использовании 0,5 и 2,0 мкМ ИУК. Аля сорта Мома эти

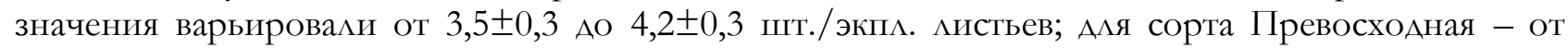

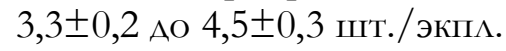

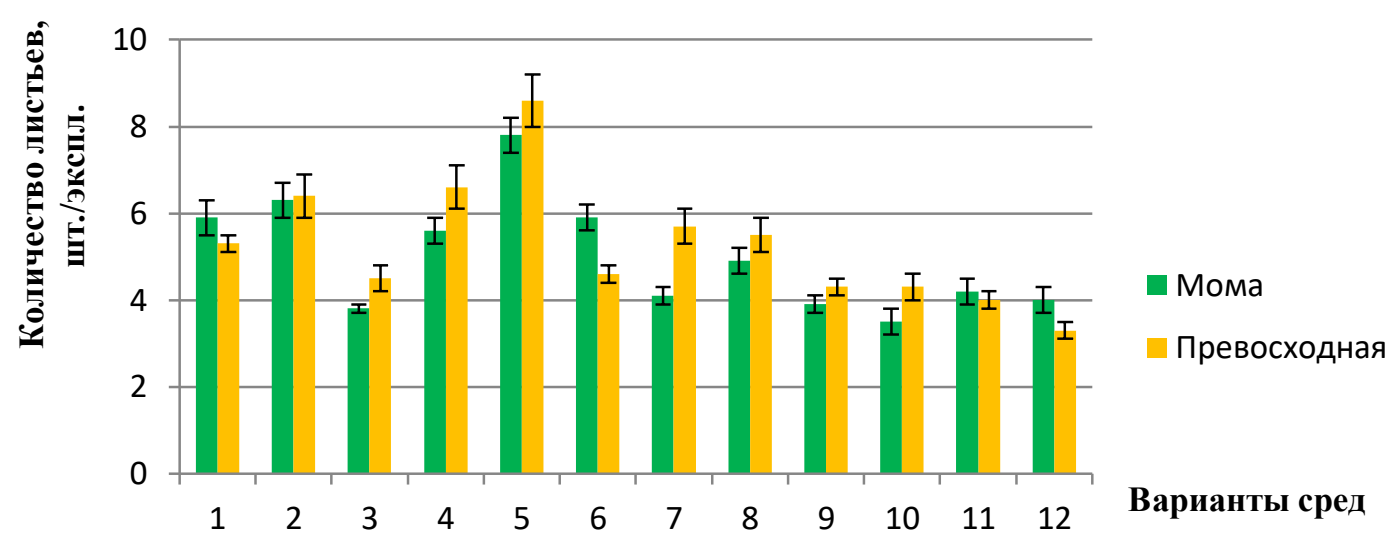

Рис. 10. ВАияние типа и концентрации ауксинов на облиственность растений-регенерантов сортов а. коломикта при укоренении в культуре in vitro

Условные обозначения: 1 - 0,5 мкМ ИМК; 2 - 0,5 мкМ НУК; 3 - 0,5 мкМ ИУК; 4 - 1 мкМ ИМК; 5 - 1 мкМ НУК; 6 - 1 мкМ ИУК; 7 - 2 мкМ ИМК; 8-2 мкМ НУК; 9 - 2 мкМ ИУК; 10 - 5 мкМ ИМК; 11 - 5 мкМ НУК; 12 - 5 мкМ ИУК

Таким образом, анализ влияния типа и концентрации ауксинов на интенсивность ризогенеза, морфологию корней и растений-регенерантов, показац, что Аля а. коломикта сорта Мома оптимальными ауксинами, при которых хорошо развиваются не только корни, но и само растениерегенерант, являются ИМК и НУК в концентрации 1,0 мкМ. А^я сорта Превосходная наиболее подходящие Аля укоренения средЫ - с 0,5 мкМ НУК и 1,0 мкМ ИМК.

Полученные нами данные согласуются с результатами исследований С.А. Муратовой с соавт. (2010) и О.И. Молкановой с соавт. (2014), которые указывают на эффективность использования низких

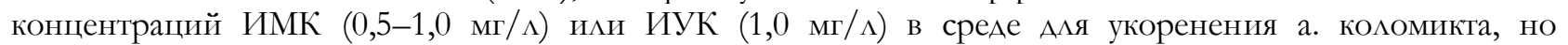
различаются с исследованиями О.И. Молкановой с соавт. (2014), выявивших преимущество использования в качестве ауксина ИУК по сравнению с ИМК.

\section{ВЫВОАЫ}

На этапе укоренения Аля женских форм сортов актинидии коломикта Мома и Превосходная наиболее эффективными являются невысокие концентрации ауксинов: 1,0 мкМ ИМК или НУК - Аля сорта Мома; 0,5 мкМ НУК или 1,0 мкМ ИМК - Аля сорта Превосходная. Статистически значимых отличий межАу формами не выявлено.

\section{СПИСОК ИСПОАЬЗУЕМОЙ АИТЕРАТУРЫ}

Бутенко Р.Г. Биология клеток высших растений in vitro и биотехнологии на их основе. - М.: ФБКПРЕСС, 1999. - 160 с.

Колбасина Э.И. Ягодные мианы и редкие кустарники. - М., 2003. - 112 с.

Малаева Е.В. Биологические и молекулярно-генетические особенности Аальневосточных виАов рода Actinidia Lindl.: Автореф. Аис. на соиск...канА. биол. наук. - М., 2008. - 21 с.

Матушкина О.В., Пронина И.Н. Особенности клонального микроразмножения ягодных культур // Пути интенсификации садоводства и селекция плодовых и ягодных культур. - Тула: Приокское книжное изА-во, 1989. - С. 167-170. 
Молканова О.И., Козак Н.В., Коновалова А.Н., Малаева Е.В. Биологические особенности Аальневосточных видов рода Actinidia Lindl. // Вестник УАмуртского ун-та, 2014. - Вып. 1. - С. $42-43$.

Муратова С.А., Шорников А.Г., Янковская М.Б., Папихин Р.В. Совершенствование метода клонацьного микроразмножения актинидии и мимонника китайского // Современное садоводство, 2010. - № 1(1). C. 96-100.

Плаксина Т.В., Бородулина И.А. ВАияние регуляторов роста на клональное микроразмножение представителей рода Актинилия // Acta Biologica Sibirica, 2016. - Том 2. - № 3. - С. 54-60.

Murashige T., Skoog F. A revised medium for rapid growth and bio assays with tobacco tissued cultures // Physiol. plant., 1962. - Vol. 15. - № 3. - P. 473-497.

\section{REFERENCES}

Butenko, R.G. (1999). Biologiya kletok vyisshih rasteniy in vitro i biotehnologii na ih osnove. Moscow: FBKPRESS (in Russian).

Kolbasina, E.I. (2003). Yagodnyie lianyi i redkie kustarniki. Moscow (in Russian).

Malaeva, E.V. (2008). Biologicheskie i molekulyarno-geneticheskie osobennosti dalnevostochnyih vidov roda Actinidia Lindl. Thesis of Doctoral Dissertation. Moscow (in Russian).

Matushkina, O.V., Pronina, I.N. (1989). Osobennosti klonalnogo mikrorazmnozheniya yagodnyih kultur (pp. 167-170). In: Puti intensifikatsii sadovodstva i selektsiya plodovyih i yagodnyih kultur. Tula: Priokskoe knizhnoe izdatelstvo (in Russian).

Molkanova, O.I., Kozak, N.V., Konovalova, L.N., Malaeva, E.V. (2014). Biologicheskie osobennosti dalnevostochnyih vidov roda Actinidia Lindl. Vestnik Udmurtskogo universiteta, 1, 42-43. (in Russian).

Murashige, T., Skoog, F. (1962). A revised medium for rapid growth and bio assays with tobacco tissued cultures. Physiol. plant., 15(3), 473-497.

Muratova, S.A., Shornikov, D.G., Yankovskaya, M.B., Papihin, R.V. (2010). Sovershenstvovanie metoda klonalnogo mikrorazmnozheniya aktinidii i limonnika kitayskogo. Sovremennoe sadovodstvo, 1(1), 96-100. (in Russian).

Plaksina, T.V., Borodulina, I.D. (2016). Vliyanie regulyatorov rosta na klonalnoe mikrorazmnozhenie predstaviteley roda Aktinidiya. Acta Biologica Sibirica, 2(3), 54-60. (in Russian). 